\title{
Mathematical Modelling of Electrically Driven Elevator via Linear Graph Method, Dynamic Response Analysis and Active Vibration Control
}

\author{
Mustafa Oğuz Nalbant ${ }^{1 *}$, Semih Sezer ${ }^{2}$ \\ ${ }^{1 *}$ Soma Vocational School, Manisa Celal Bayar University, Soma, Manisa, Turkey \\ ${ }^{2}$ Mechanical Engineering, Yildız Technical University, Besiktas, Istanbul, Turkey \\ *mustafa.nalbant@cbu.edu.tr
}

Received: 31 July 2018

Accepted: 17 September 2019

DOI: $10.18466 /$ cbayarfbe. 449655

\begin{abstract}
Viscous friction occurs between the roller guide shoes and guide rail because of the grease layer.This friction causes to vibration on the cage. This study's aim is an investigation and active control of that vibration for passengers. Initially, the passenger elevator's dynamics modeling is carried out by Linear Graph Method. The DC motor and AC motor parameters are used in the system modeling separately. Then, vibrations occurred on the elevator cabin are observed. Finally, the effect of vibrations is reduced with the aid of an active controller. The time and frequency responses are compared for two kinds of the motor.
\end{abstract}

Keywords: Elevator system, Linear Graph Method, System Modeling, Vibration, Fuzzy Logic Controller.

\section{Introduction}

Elevators are used mainly for human transfer. They are transportation vehicle traveling on guide rails vertically and work with an electric drive from machine room. It started as lifting machine working with a hand which made by Archimedes in B.C.236, then as hydraulic drive 1830s; it was improved with using a steam engine in 1835s. The first elevator was established in a business center in New York by Elisha Graves Otis in 1857, using modern technology. After that, the elevator machine was manufactured by Otis in 1889. It had a hoist drum and with an endless screw mechanism related directly with an electrical motor. Otis Company manufactured the elevator which had non-reducer and driving pulley in 1904. Sensitive level order in elevators was used to start in 1915. Elevators with group control which haven't wired and have been supplied with electromagnetic control have become popular in the last decades [1].

However, usage of elevators showed increase slowly in the last 20th century and has increased extremely in the early 21 st century. In fact, it has become an irreplaceable transport vehicle for human's life. This reason was undoubtedly the rising of buildings.

Usage of elevators in high buildings passed needing improvements and innovations as speed and traffic.
Especially speed factor causes the comfort problems as security rumble and vibration in elevators. Nowadays, the purpose of the elevator systems enables human's security and comfort and also the reduction of the traveling time [2].

It is obvious that the resistance values caused by the movement and friction of the roller guide shoes on the guide rail surface change depending on speed. For this reason, in high-speed elevators, the rails are constantly lubricated and it is aimed to reduce the loss of skating by the oil slip feature. In the lubrication process, many factors must be taken into account. In particular, if the preferred grease oil is more viscous than necessary, it reduces the performance by forcing the movement of the cabin. Similar, wrong or dense grease oil causes a lot of disruption to passenger comfort. For instance, a vertical swing of the cabin on departure and arrival or in the moments of acceleration and deceleration and occlusion of the roller guide shoes [3].

In this study, one of the factors that reduce the quality of cruise control is defined as viscous friction between the guide rail and the roller guide shoes and defined with a non-linear parameter. The vibrations caused by this viscous friction are taken into consideration while the elevator is in operation and the passenger's comfort is 
aimed at active control. Initially, the equations of motion of the elevator model, shown in Figure 1, have been obtained by using Linear Graph method. This method is used in modeling of multi-disciplinary systems as graphically. In the second part, the equations of motion of the elevator model were simulated with the MATLAB Simulink interface and performed a dynamic analysis for system's each state variable. In the last part, active control of the acceleration that disturbs the comfort of the system is provided. The use of fuzzy logic controller allows the control of the non-linear motion of the system. In the literature, a fuzzy logic controller seems to be applied successfully for many different systems. For instances, fuzzy logic and PD controllers are designed for a multidegree-of-freedom structure with an active tuned mass damper (ATMD) to suppress earthquake-induced vibrations. Performance analysis of the conventional PID controller and fuzzy logic controller has been done by the use of MATLAB and Simulink and in the end comparison of various time domain parameters is done to prove that the fuzzy logic controller has small overshoot and fast response as compared to PID controller, a fuzzy control that uses rules based on a skilled human operator's experience is applied to automatic train operations in [4]. An attempt has been made to review the applications of fuzzy logic based models in renewable energy systems namely solar, wind, bioenergy, micro-grid and hybrid applications by [5].

\section{Material and Method}

\subsection{Linear Graph Method}

Linear graph method, invented by Leonhard Euler in 1736, was applied to the modeling and analysis of onedimensional physical systems in the [6]. The basic method of this modeling approach was established during this period, and subsystem analysis methods were developed to facilitate the modeling of very large electrical networks by Roe in [7]. Linear graph theory was extended to the modeling of multi-dimensional particle mass systems in [8] and to spatial multıdisciplinary systems of rigid bodies in the 1980s and 1990s by Baciuin [9] and McPhee in [10].

Graph methods can be used to generate equations in terms of user-selected coordinates, including absolute or joint or indirect coordinates, or some combination of the three.

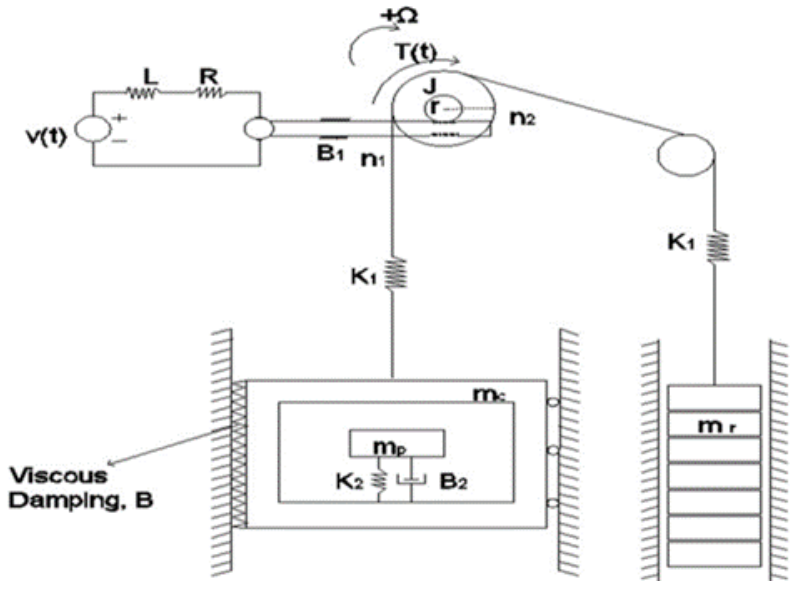

Figure 1. Physical model of the electrically driven elevator.

By selecting coordinates that are well-suited to a given problem, one can reduce the number and complexity of the governing equations.

Given that linear graphs were originally applied to electrical networks, the extension of graph-theoretic methods to the modeling of mechatronic multidisciplinary systems are natural and straightforward. From a single linear graph of the entire system, the coupled equations for the electrical and mechanical domain are systematically derived [10].

Linear graph method is a graphical method which makes enabler the solving of the multidisciplinary systems as systems generate with minimum twice of a mechanic, electric, fluid and thermal etc. discipline. It is successful method of obtaining real-like results. Withdrawing of the linear graph, Physical system's type loses its significance in terms of analysis and after this state; a formal variety show is obtained which enable to perform same analysis and syntheses method on varied engineering systems [11].In this paper, the linear graph method used for carrying the elevator system's dynamics model which shown in Figure 1 and its graph is drawn as shown in Figure 2a.

The system state's variables are determined by use normal tree and tree bond Figure $2 \mathrm{~b}$ and $2 \mathrm{c}$.

State variables;

$I_{2}, w_{9}, F_{12}, v_{14}, F_{15}, v_{17}$

Primary variables;

$V_{1}, V_{3}, V_{4}, w_{7}, w_{9}, v_{11}, v_{14}, v_{17}, I_{2}, T_{5}, T_{6}, T_{8}, T_{10}, F_{12}, F_{13}, F_{15}, F_{16}$

Secondary variables;

$I_{1}, I_{3}, I_{4}, T_{7}, T_{9}, F_{11}, F_{14}, F_{17}, V_{2}, w_{5}, w_{6}, w_{8}, w_{10}, v_{12}, v_{13}, v_{15}, v_{16}$ 
Then from the linear graph shown Fig. 2a; the number of the arm as $\mathrm{B}=19$, number of the node as $\mathrm{N}=9$, number of the voltage source as $\mathrm{SA}=1$, and number of the current source as ST $=1$ are defined and the total number of the equations are found as;

$\mathrm{B}-\mathrm{S}=17$ element equations

$\mathrm{N}-1-\mathrm{SA}=8$ continuity equations

$\mathrm{B}-\mathrm{N}+1-\mathrm{ST}=9$ circuit equations
The primary and secondary equations are used for define all equations shown in Table 1, [11].

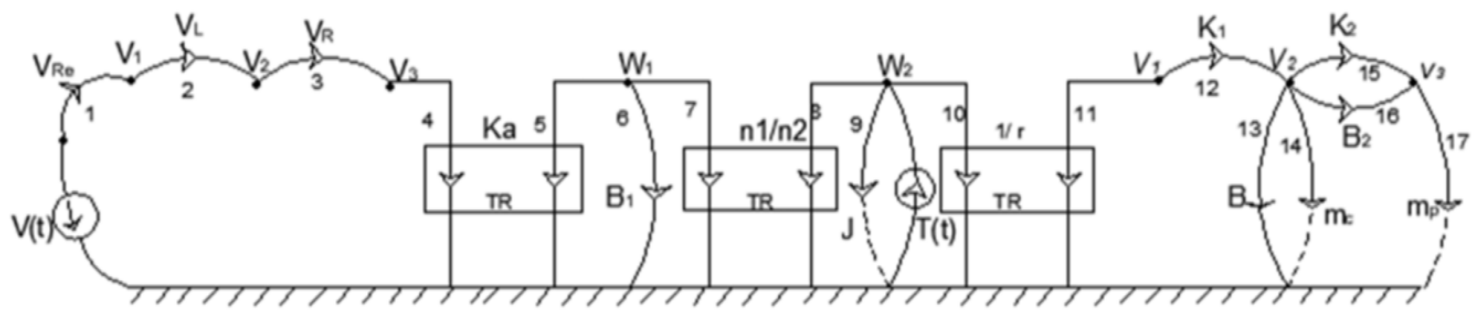

a)

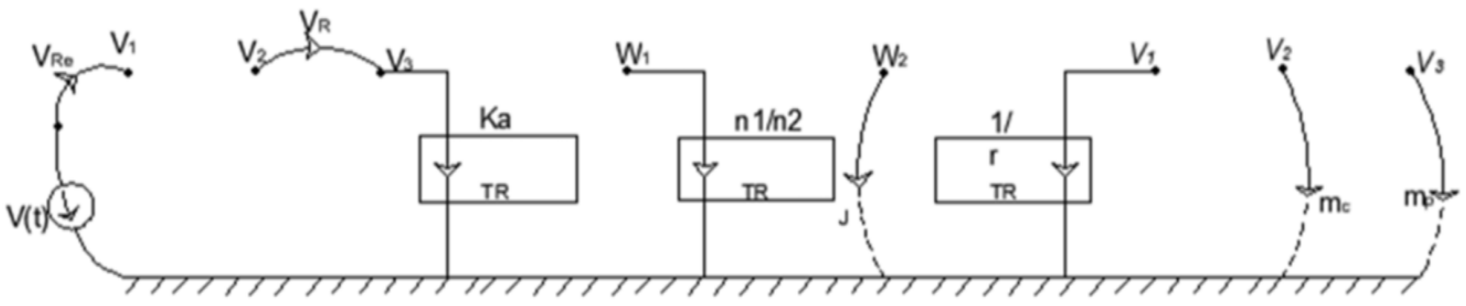

b)<smiles>[Y]C([Y])=[V]</smiles>
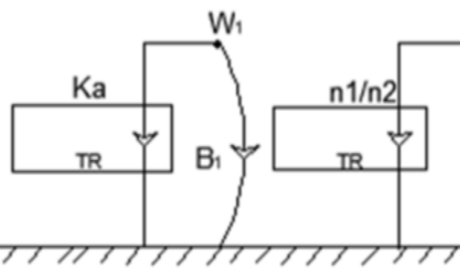

$W_{2}$
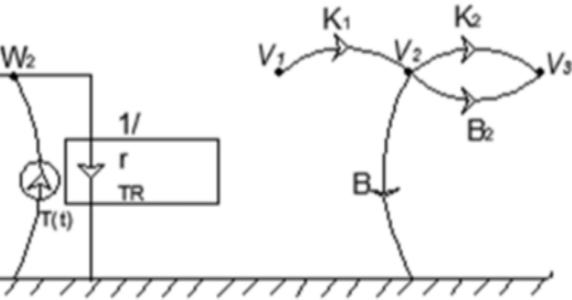

c)

Figure 2. a) Linear graph b) Normal tree and c) Tree bond of electrically driven elevator system.

Table 1. System equations.

\begin{tabular}{|l|l|l|l|l|l|l|l|}
\hline \multicolumn{2}{|l|}{ Element Equations } & \multicolumn{2}{l|}{ Continuity Equations } & \multicolumn{2}{l|}{ Circuit Equations } \\
\hline 1 & $V_{1}=R_{e} I$ & 10 & $T_{10}=-r F_{11}$ & 18 & $I_{1}=I_{2}$ & 26 & $V_{2}=V(t)-V_{1}-V_{3}-V_{4}$ \\
\hline 2 & $\frac{d I_{2}}{d t}=\frac{1}{L} V_{2}$ & 11 & $v_{11}=\frac{w_{10}}{r}$ & 19 & $I_{3}=I_{2}$ & 27 & $w_{5}=w_{7}$ \\
\hline 3 & $V_{3}=R I_{3}$ & 12 & $\frac{d F_{12}}{d t}=K_{1} v_{12}$ & 20 & $I_{4}=I_{2}$ & 28 & $w_{6}=w_{7}$ \\
\hline 4 & $V_{4}=K_{a} \cdot w$ & 13 & $F_{13}=v_{13} B$ & 21 & $T_{7}=-T_{5}-T_{6}$ & 29 & $w_{8}=w_{9}$ \\
\hline
\end{tabular}




\begin{tabular}{|l|l|l|l|l|l|l|l|}
\hline 5 & $T_{5}=\frac{1}{K_{a}} I_{4}$ & 14 & $\dot{\boldsymbol{v}}_{\mathbf{1 4}}=\frac{\boldsymbol{F}_{\mathbf{1 4}}}{\boldsymbol{m}_{c}}$ & 22 & $T_{9}=T(t)-T_{8}-T_{10}$ & 30 & $w_{10}=w_{9}$ \\
\hline 6 & $T_{6}=B_{1} w_{6}$ & 15 & $\frac{d F_{15}}{d t}=K_{2} v_{15}$ & 23 & $F_{11}=-F_{12}$ & 31 & $v_{12}=v_{11}-v_{14}$ \\
\hline 7 & $w_{7}=\frac{n_{1}}{n_{2}} w_{8}$ & 16 & $F_{16}=B_{2} v_{16}$ & 24 & $F_{14}=F_{12}-F_{13}-F_{15}-F_{16}$ & 32 & $v_{13}=v_{14}$ \\
\hline 8 & $T_{8}=-T_{7} \frac{n_{2}}{n_{1}}$ & 17 & $\frac{d v_{17}}{d t}=\frac{F_{17}}{\boldsymbol{m}_{p}}$ & 25 & $F_{17}=F_{15}+F_{16}$ & 33 & $v_{15}=v_{14}-v_{17}$ \\
\hline 9 & $\frac{d w_{9}}{d t}=T_{9} \frac{1}{J}$ & & & & & 34 & $v_{16}=v_{14}-v_{17}$ \\
\hline
\end{tabular}

$V:$ Voltage, $I:$ Current, $R:$ Motor resistance constant, $m:$ Mass, $B:$ Friction constant, $T:$ Torque, $J:$ Inertia, $F:$ Force, $w:$ Angular velocity,

$v$ : Velocity, $r$ : Radius, $K_{a}$ : Electromechanical switchgear constant, $K$ : Spring Constant, $L:$ Motor inductance constant,

Table 2. Element equations.

\begin{tabular}{|l|l|l|l|}
\hline 35 & $\frac{d I_{2}}{d t}=\frac{1}{L}\left(V(t)-V_{1}-V_{3}-V_{4}\right)$ & 44 & $T_{5}=-\frac{1}{K_{a}} I_{2}$ \\
\hline 36 & $\frac{d w_{9}}{d t}=\frac{1}{J}\left(T(t)-T_{8}-T_{10}\right)$ & 45 & $T_{6}=B_{1} w_{7}$ \\
\hline 37 & $\frac{d F_{12}}{d t}=K_{1}\left(v_{11}-v_{14}\right)$ & 46 & $T_{8}=\frac{n_{2}}{n_{1}}\left(T_{5}+T_{6}\right)$ \\
\hline 38 & $v_{14}=\frac{\left(F_{12}-F_{13}-F_{15}-F_{16}\right)}{m_{c}}$ & 47 & $T_{10}=r F_{12}$ \\
\hline 39 & $\frac{d F_{15}}{d t}=K_{2}\left(v_{14}-v_{17}\right)$ & 48 & $v_{11}=\frac{w_{9}}{r}$ \\
\hline 40 & $\frac{d v_{17}}{d t}=\frac{\left(F_{15}+F_{15}\right)}{m_{p}}$ & 49 & $F_{13}=B \dot{v}_{14}$ \\
\hline 41 & $V_{1}=R_{e} I_{2}$ & 50 & $w_{7}=\frac{n_{1}}{n_{2}} w_{9}$ \\
\hline 42 & $V_{3}=R I_{2}$ & 51 & $F_{16}=B_{2}\left(v_{14}-v_{17}\right)$ \\
\hline 43 & $V_{4}=\frac{w_{5}}{K_{a}}$ & & \\
\hline
\end{tabular}

The state equations $35,36,37,38,39$, and 40 are regulated in state variables;

System's equations of state variable are obtained as follow;

$$
\begin{aligned}
& \frac{d I_{L}}{d t}=\frac{1}{L} V(t)-\frac{\left(R_{e}+R\right)}{L} I_{L}-\frac{n_{1}}{K_{a} L n_{2}} w_{J} \\
& \frac{d w_{J}}{d t}=\frac{1}{J} T(t)+\frac{n_{2}}{n_{1} J K_{a}} I_{L}-\frac{B_{1}}{J} w_{J}
\end{aligned}
$$


$\frac{d F_{12}}{d t}=\frac{K_{1}}{r} w_{J}-K_{1} v_{m_{c}}$

$\frac{d \nu_{m_{c}}}{d t}=\frac{1}{m_{c}} F_{K_{1}}-\frac{B}{m_{c}} \dot{v}_{m_{c}}-\frac{1}{m_{c}} F_{K_{2}}-\frac{B_{2}}{m_{c}} v_{m_{c}}+\frac{B_{2}}{m_{c}} v_{m_{P}}$

$\frac{d F_{K_{2}}}{d t}=K_{2} v_{m_{c}}-K_{2} v_{m_{p}}$

$\frac{d v_{m_{p}}}{d t}=\frac{1}{m_{p}} F_{K_{2}}+\frac{B_{2}}{m_{p}} v_{m_{c}}-\frac{B_{2}}{m_{p}} v_{m_{p}}$

That state equations are written in Matrix form as follow;

$\left[\begin{array}{c}\dot{I}_{L} \\ \dot{w}_{J} \\ \dot{F}_{K_{1}} \\ \dot{v}_{m_{c}} \\ \dot{F}_{K_{2}} \\ \dot{v}_{m_{p}}\end{array}\right]=\left[\begin{array}{cccccc}-\frac{\left(R_{e}+R\right)}{L} & -\frac{n_{1}}{K_{a} L n_{2}} & 0 & 0 & 0 & 0 \\ \frac{n_{2}}{n_{1} J K_{a}} & -\frac{B_{1}}{J} & 0 & 0 & 0 & 0 \\ 0 & \frac{K_{1}}{r} & -K_{1} & 0 & 0 & 0 \\ 0 & 0 & \frac{B}{m_{c}\left(m_{c}+B\right)} & -\frac{B}{m_{c}\left(m_{c}+B\right)} & -\frac{B_{2} B}{m_{c}\left(m_{c}+B\right)} & \frac{B_{2} B}{m_{c}\left(m_{c}+B\right)} \\ 0 & 0 & 0 & \frac{K_{2}}{m_{p}} & 0 & \frac{K_{2}}{m_{p}} \\ 0 & 0 & 0 & \frac{B_{2}}{m_{p}}\end{array}\right]\left[\begin{array}{c}I_{L} \\ w_{J} \\ F_{K_{1}} \\ v_{m_{c}} \\ F_{K_{2}} \\ v_{m_{p}}\end{array}\right]+\left[\begin{array}{ll}\frac{1}{L} & 0 \\ 0 & \frac{1}{J}\end{array}\right]\left[\begin{array}{l}V(t) \\ T(t)\end{array}\right]$

\subsection{Dynamic Analysis of The Elevator System}

In dynamic systems, a number of questions related to system performance are often of interest. In some cases, to study performances of the vehicle systems. The interested reader can see [12], to present the evaluation of the dynamic response of structural systems with physical and geometrical nonlinearities in [13] and [14]. In this study, the problem of the dynamic system is about passenger comfort that travels in the elevator. The vibrations occur on the system because of especially viscous damping, between the roller guide shoes and guide rail and the other negative factors.
In all dynamic analyzes, it is important to create a correct mathematical model of the system. Many physical systems of interest to engineers may be represented by a set of mathematical equations that form a state-determined system model of the system [15].

In the previous step, linear graph method is given mathematical equations of elevator system. System's equations of state variable are mathematical equations of elevator system. Parameters of the elevator system are given in Table 3.

Table 3. System parameters [16] and [17].

\begin{tabular}{cccc}
\hline Parameter & Value & Parameter & Value \\
\hline $\mathrm{V}$ & $500 \mathrm{Volt}$ & $\mathrm{n}_{1}$ & $1430 \mathrm{rpm}$ \\
$\mathrm{B}_{1}$ & $980 \mathrm{Ns} / \mathrm{m}$ & $\mathrm{n}_{2}$ & $190 \mathrm{rpm}$ \\
$\mathrm{T}$ & $158 \mathrm{nNm}$ & $\mathrm{M}_{\mathrm{c}}$ & $80 \mathrm{~kg}$ \\
$\mathrm{~B}_{2}$ & $300 \mathrm{Ns} / \mathrm{m}$ & $\mathrm{M}_{\mathrm{p}}$ & $500 \mathrm{~kg}$
\end{tabular}




$\begin{array}{cccc}\mathrm{R} & 5,65 \mathrm{ohm} & \mathrm{J} & 0,481 \mathrm{~kg} / \mathrm{m}^{2} \\ \mathrm{~L} & 2,90.10^{-3} \mathrm{H} & \mathrm{v} & 20 \mathrm{~m} / \mathrm{s} \\ \mathrm{Re} & 0,445 \mathrm{ohm} & \beta & 300 \\ \mathrm{Ka} & 2,39.10^{-2} \mathrm{Nm} / \mathrm{A} & \mathrm{B} & \beta \operatorname{sign}(v)|v| \\ \mathrm{K}_{1} & 145000 \mathrm{~N} / \mathrm{m} & \mathrm{r} & 0,1 \mathrm{~m} \\ \mathrm{~K}_{2} & 2500 \mathrm{~N} / \mathrm{m} & & \end{array}$

Many commercially available dampers do display nonlinear viscous behavior. For example, the approximate optimal nonlinear tuned mass damper is in fact very close to the true optimum is shown by stochastic simulation in [17]. Terenzi was studied Nonlinear viscous damping characterizes a special class of fluid viscous dampers recently utilized in the field of vibration control as baseisolation devices or viscoelastic elements included in steel braces of framed structures are examples of other nonlinear types of behavior experienced in engineering practice in [18]. Because of that, viscous damping "B" that occurs between the roller guide shoes and the guide rail is assumed to be nonlinear as shown in Table 3 .

\subsection{Active Vibration Controller Design with Fuzzy Logic Algorithm}

Viscous friction between elevator cage and guide rail produce undesired vibrations on the cage. If these vibrations are not minimized, they can cause uncomfortable transport. In this article, an active vibration controller is designed by means of the Fuzzy Logic algorithm to improve passenger's comfort. One vertical actuator is designed and this controller actuator is added to the cabin.

The field of fuzzy sets and logic was first introduced by LotfiZadeh in [19]. To minimize the cage vibrations the controller is placed between the cabin and the drive pulley in the system. Fuzzy Logic controller which was applied to simulation is as in Figure 4. The controller has worked on the some rules were created in the fuzzy Mamdani interface of MATLAB program as shown in the table and were successfully applied to the simulation.

\subsection{Vertical Control Designer}

The vertical rail disturbance effect on the elevator cabin is defined as seen in Figure 3. When the cabin moves forward in the vertical direction and rotates about the center of mass by a roll and pitch angles, one vertical error occurs at the central point of the cabin. This vertical error is the displacement difference from the reference position that is the equilibrium point of the cabin. The vertical displacement error and the derivative of the lateral displacement error of cabin at the central point of cabin body are defined as and in equation (58) $e=r e f_{Z_{c}}-\left(Z_{c}\right)$ and $\dot{e}=r e f_{\dot{Z}_{c}}-\left(\dot{Z}_{c}\right)$

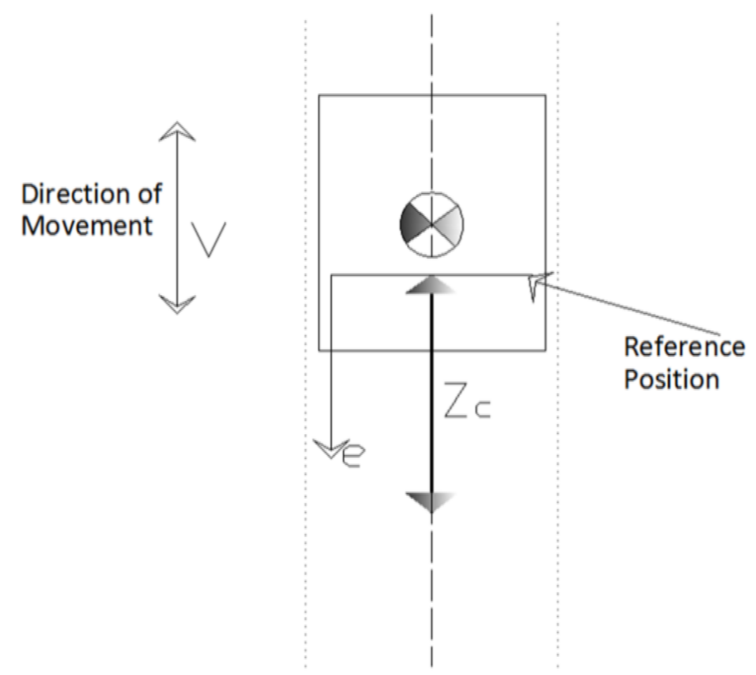

Figure 3. The Vertical displacement errors of elevator cabin.

The vertical rail disturbance function is considered as sine function that excites the cabin body lateral vibrations so the reference value for vertical error or target value and the reference value for vertical error derivative are considered as zero.

The vertical displacement error and the derivative of the vertical displacement error is the input of the controller. Additionally, the output of the controller is the block diagram of a vertical fuzzy logic controller for the central point is seen in Figure 4. 


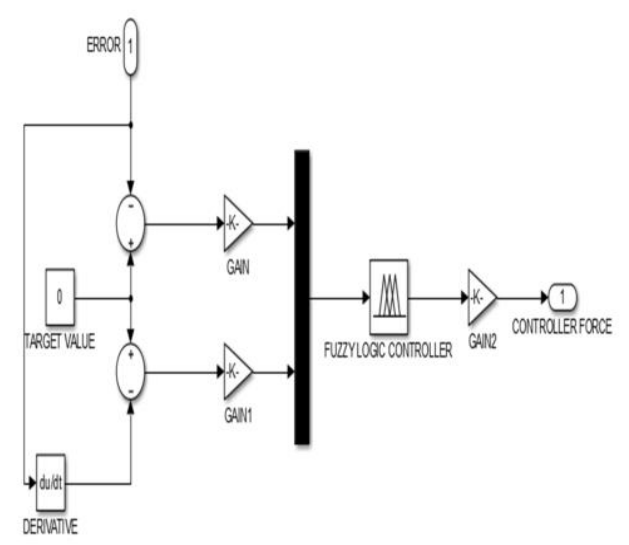

Figure 4. Block diagram of fuzzy logic controller.

Table 4. Rule-base design for Fuzzy logic controller.

\begin{tabular}{|c|c|c|c|}
\hline \multirow{2}{*}{ Displacement Error (e) } & \multicolumn{3}{|c|}{ Derivative of Amplitude Error } \\
\cline { 2 - 4 } & $\mathrm{N}$ & $\mathrm{Z}$ & $\mathrm{P}$ \\
\hline $\mathrm{NB}$ & $\mathrm{NBU}$ & NMU & NSU \\
\hline NS & NMU & NSU & ZU \\
\hline Z & NSU & ZU & PSU \\
\hline PS & ZU & PSU & PMU \\
\hline PB & PSU & PMU & PBU \\
\hline
\end{tabular}

$\mathrm{NB}=$ negative big, $\mathrm{NS}=$ negative small, $\mathrm{Z}=$ zero, $\mathrm{PB}=$ positive big, $\mathrm{PS}=$ =positive small, $\mathrm{N}=$ negative, $\mathrm{P}=$ positive, NBU= negative big error, NSU= negative small error, $\mathrm{NMU}=$ negative medium error, $\mathrm{NMU}=$ negative small error, $\mathrm{ZU}=$ zero error, $\mathrm{PSU}=$ positive small error, $\mathrm{PMU}=$ positive medium error, $\mathrm{PBU}=$ positive big error.
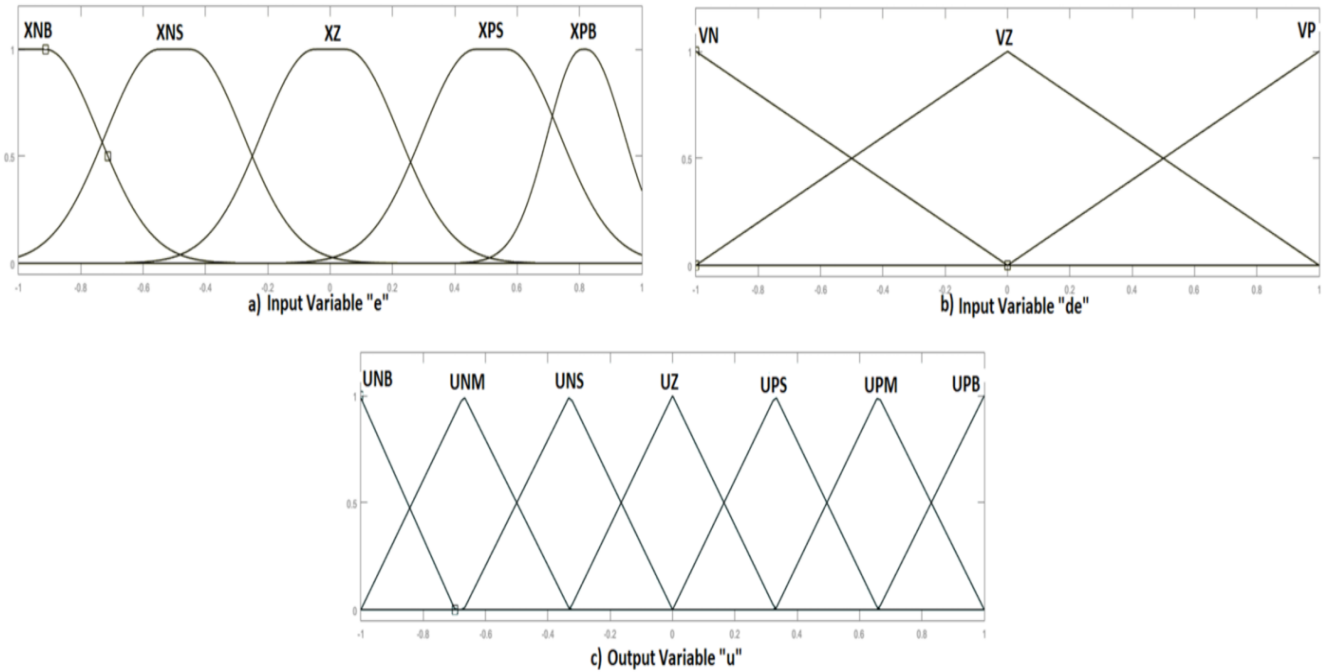

Figure 5. Membership functions of (a) displacement error input, (b) derivative of displacement error input and (c) controller output. 


\section{Results}

Simulink is an environment for multidomain simulation and Model-Based Design for dynamic systems [20]. In this section, the active vibration control in the elevator system is simulated by using MATLAB Simulink Toolbox. Eqs. (52) - (57) used as state equations and placed in SIMULINK S-function blocks.

Additionally, the sinusoidal input is added Simulink as representative of vertical disruptive effect which occurs because of friction between the rollers guides shoes on rail surface.

Simulation results are shown in Figures 6, 7, 8, and 9. The graphics in the panel (a) and (b) of the Figures are belonging to $\mathrm{AC}$ and $\mathrm{DC}$ motor is driven elevator systems, respectively. When the active controller is added to the system, the improvement in steady state is clearly observed in Figures $6,7,8$ and 9.
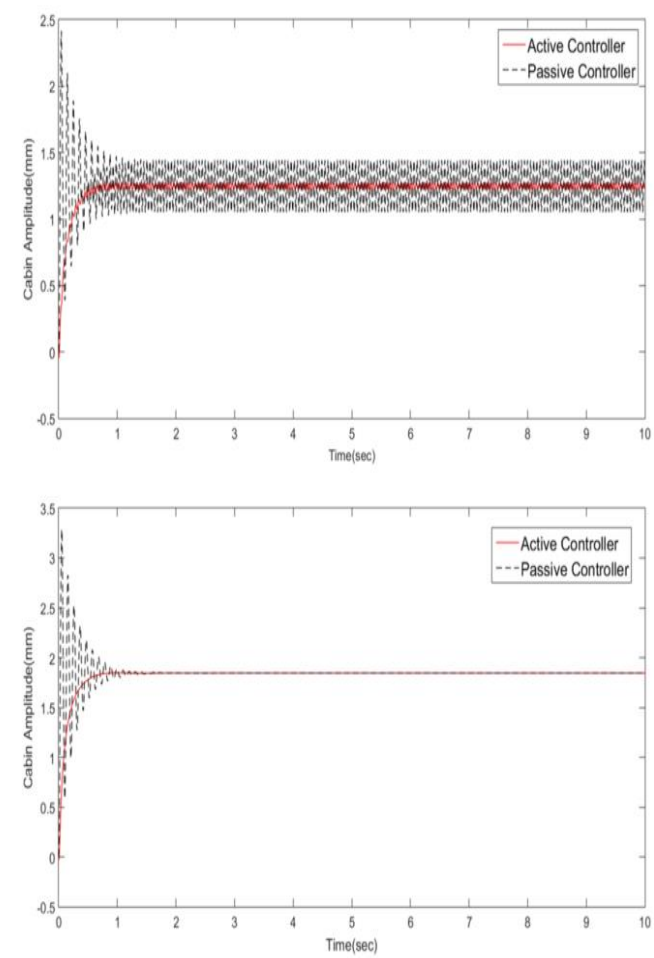

Figure 6. Time response of cabin amplitude for vertical motion graph.

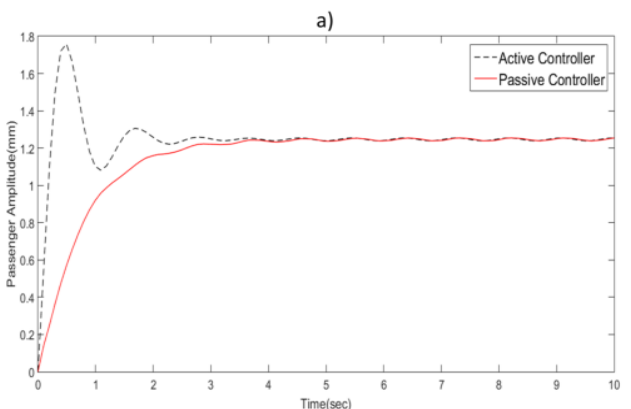

b)

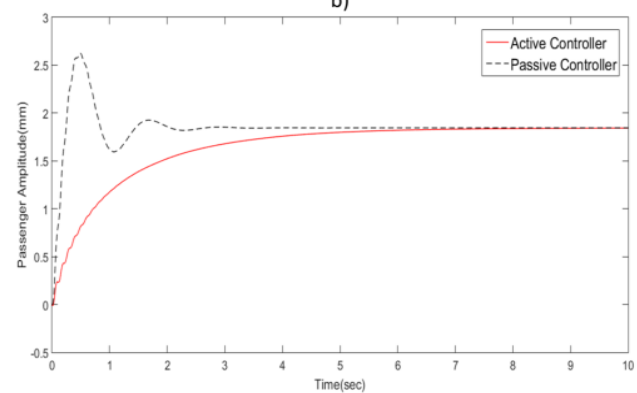

Figure 7. Time response of passenger amplitude for vertical motion graph.
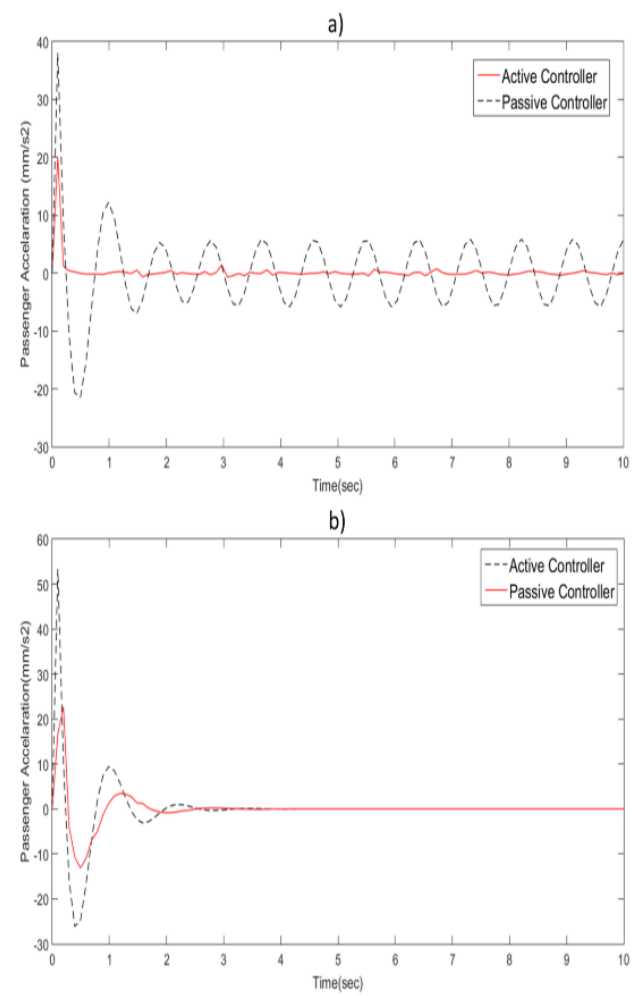

Figure 8. Time response of cabin acceleration for vertical motion graph. 


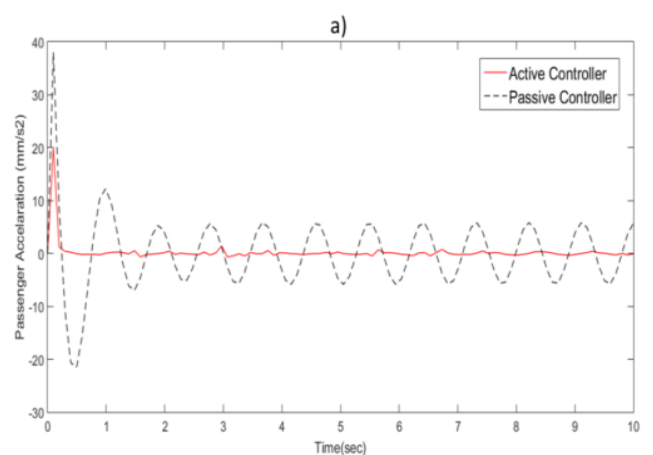

b)

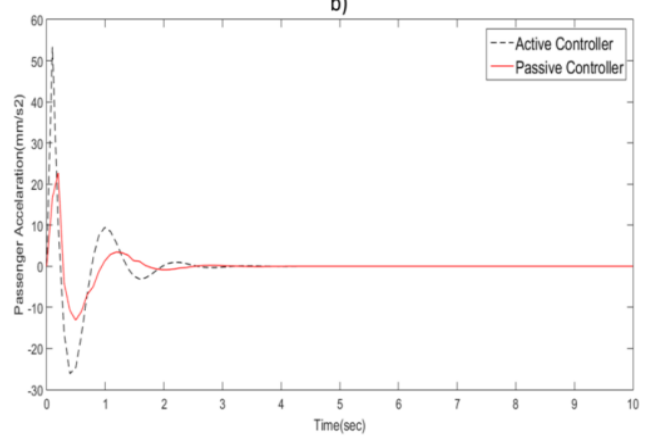

Figure 9. Time response of passenger acceleration for vertical motion graph.

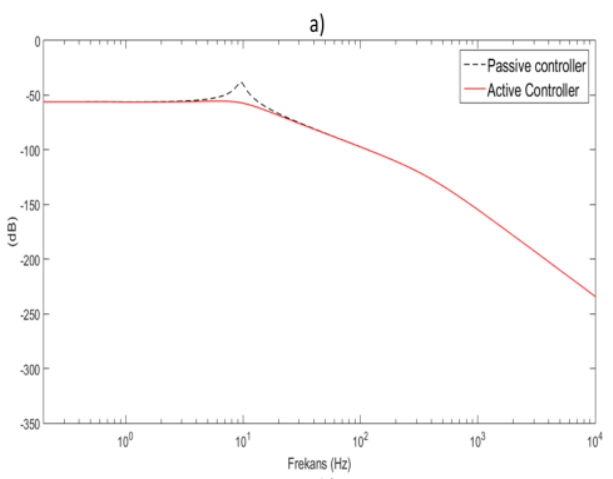

b)

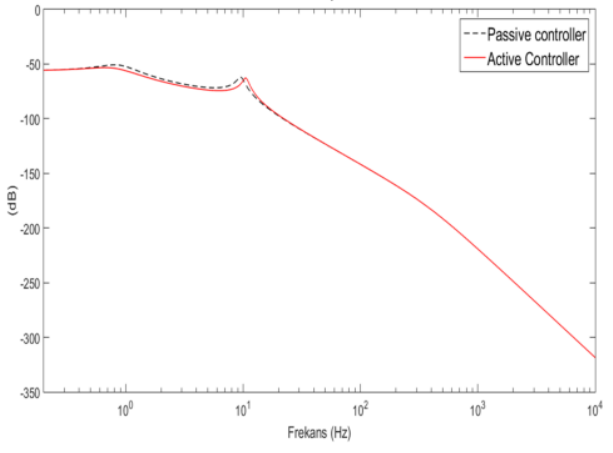

Figure 10. Bode graph for motions of Cabin and Passenger, respectively from left to right.
The change in engine speed and the amplitude of the passenger who exposed during the time span including a one-step start-stop motion is also observed in Figure 11.
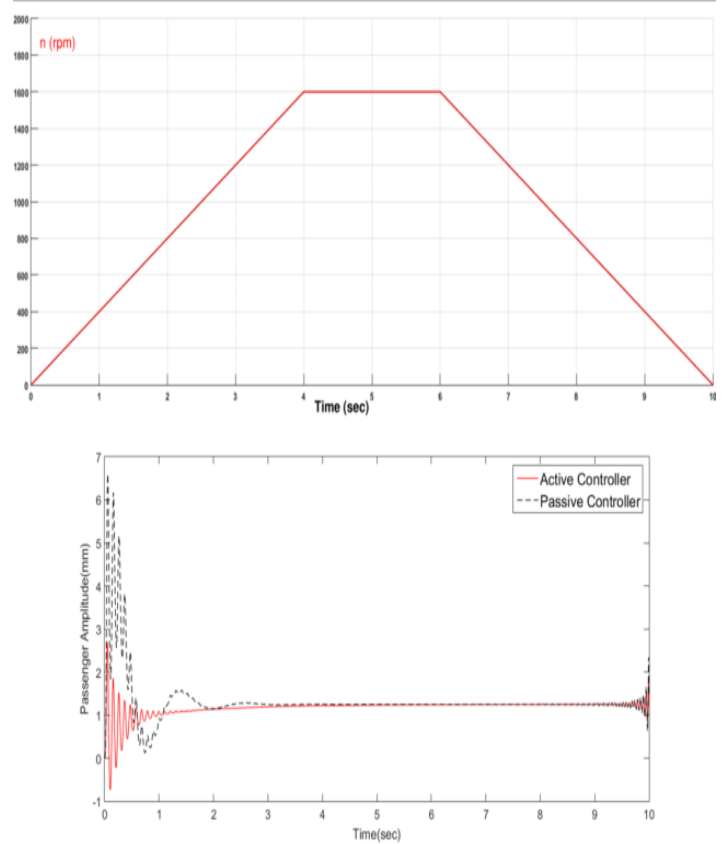

Figure 11. Time response of passenger amplitude for elevator's departure - arrival motion.

\section{Conclusion and Discussion}

The viscous friction occurs between the roller guide shoes and the cabin because of the dense or wrong grease oil for the elevator system. This situation generates vibration and discomforts passenger who use the lift. In order to investigate that vibration, firstly, the mathematical model of the system is constituted by using the Linear Graph Method. The state equations of the system are obtained with normal tree and tree bonds. Secondly, time responses of the state equations are investigated. Then fuzzy logic active controller is impressed to the system in order to improve that state equations response. DC and AC drive motor responses are investigated together. The results are obtained separately and compared. The discussions about the study are as follows.

- When the results of the active and passive controller compared, it is seen that the active controller performs effectively. It is also seen that the sudden accelerations of the cabin and passenger are improved.

- Frequency responses of the active and passive controller are compared in Fig. 10 and it is seen that the active controller is performed successfully here too.

- According to elevator international comfort standards, the maximum acceleration value can be $0.8 \mathrm{~m} / \mathrm{s} 2$. When the results of the active controller examined at the Fig. 7 (Time response of passenger acceleration for vertical 
motion graph), it is seen that the acceleration values change between $0.25-0.5 \mathrm{~m} / \mathrm{s} 2$.

- Active controller results are also successful, even for sinusoidal or one-step start-stop motion inputs. It infers that the FLC based active controller is designed successfully for the system.

\section{Ethics}

There are no ethical issues after the publication of this manuscript.

\section{References}

1. Dursun, M, Saygın, A. 2006. Bir asansör tahrik sistemi için bulanık mantık denetimli anahtarlamalı relüktans motor sürücüsüta sarımı. Journal of Engineering Sciences; 12, 151-160.

2. Bolat, B. 2006/2. The Simulation and Optimization of Lift Control Systems with Genetic Algoritms. Journal of engineering and natural sciences.

3. Erdem, E, Dallı, L. Asansörlerde Yağlamalarin Önemi, EMO Asansör Sepmpozyumu, 2008, Izmir, Turkey, pp 214-237.

4. Yasunobu, S, Miyamoto, S, Ihara, H. 1983. Fuzzy Control for Automatic Train Operation System. IFAC Proceedings Volumes; 3339.

5. Suganthi, L, Iniyan, S, Anand, A.S. Applications of fuzzy logic in renewable energy systems. A review, Renewable and Sustainable Energy Reviews, 2015, pp 585-607.

6. Koenig, H.E, Tokad, Y, Kesavan, H.K. Analysis of Discrete Physical Systems, McGraw-Hill Press: New York, USA, 1967.

7. Roe, P. Networks and Systems; Addison-Wesley Press: Reading, MA, 1966.

8. Andrews, G.C, Kesavan, H.K. The vector-network model: A new approach to vector dynamics, Mechanism and Machine Theory, 1975, pp 57-75.

9. George B, Kesavan H.K. From particle-mass to multibody systems: graph-theoretic modeling, IEEE Trans. Systems, Man, and Cybernetics, 1997, pp 244-250.

10. McPhee, J. Automatic Generation of Motion Equations for Planar Mechanical Systems Using the New Set of 'Branch Coordinates', Mech. Mach. Theory, 1998, pp 805-823.

11. Y. Ercan, Mühendislik Sistemlerinin Modellenmesive Dinamiği; Literatür Yayınları: Istanbul, Turkey, 2009, pp 220-221.

12. Liang, B, Zhu, D, Cai, Y. 2001. Dynamic Analysis of the VehicleSubgrade Model of A Vertical Coupled System. Journal of Sound and Vibration; 79-92.

13. Wilson E. L, Farhoomand, I, Bathes, K.J. 1972. Nonlinear dynamic analysis of complex structures. Earthquake Engineering Structural Dynamics; 241-252.

14. Muscolino, G, Ricciardi, G, Impollonia, N. 2000. Improved dynamic analysis of structures with mechanical uncertainties under deterministic input, Probabilistic Engineering Mechanics; 199-212.

15. Derek, R, David N.W. System Dynamics - An Introduction; Prentice Hall Upper Saddle River Press: New Jersey, USA, 1997.
16. Imrak, C.E. Gerdemli I. Asansörler ve Yürüyen Merdivenler; Birsen Yayınevi: Istanbul, Turkey, 2000.

17. Rüdinger, F. 2007. Tuned mass damper with nonlinear viscous damping. Journal of Sound and Vibration; 932-948.

18. Terenzi, G. 1999. Dynamics of SDOF systems with nonlinear viscous damping. Journal of Engineering Mechanics; 956-963.

19. Zadeh, L.A. Fuzzy sets, Information and Control, 1965, pp 338-353.

20. Cheung, J.Y.M, Kamal, A.S. Fuzzy Logic Control of refrigerant flow, UKACC International Conference on Control, 1996, pp 2-5. 